J. Dairy Sci. 95:6379-6383

http://dx.doi.org/10.3168/jds.2012-5623

(C) American Dairy Science Association ${ }^{\circledR}, 2012$.

\title{
Short communication: Simultaneous analysis of reducing sugars and 5-hydroxymethyl-2-furaldehyde at a low concentration by high performance anion exchange chromatography with electrochemical detector, compared with HPLC with refractive index detector
}

\author{
Y.-G. Guan, ${ }^{*}$ P. Yu, ${ }^{\star}$ S.-J. Yu, ${ }^{*}{ }^{1}$ X.-B. Xu, ${ }^{*}$ and X.-L. Wu \\ ${ }^{*}$ College of Light Industry and Food Sciences, South China University of Technology, Guangzhou 510640, China \\ †Guangdong Province Key Laboratory for Green Processing of Natural Products and Product Safety, Guangzhou 510631, China
}

\begin{abstract}
A simultaneous analysis of reducing sugars and 5-hydroxymethyl-2-furaldehyde of the Maillard reaction products was detailed. It was based on a high performance anion exchange chromatography with electrochemical detector system and an HPLC with refractive index detector. Results showed that high performance anion exchange chromatography with electrochemical detector using a CarboPac PA-1 column (Dionex Corp., Sunnyvale, CA) was more suitable for reducing sugars and 5-hydroxymethyl-2-furaldehyde determination, especially for trace analysis. The lowest detectable limit of reducing sugars and 5-hydroxymethyl-2-furaldehyde was $0.00005 \mathrm{~mol} / \mathrm{L}$ in this experiment. However, HPLC with a refractive index detector always produces a tailing peak for 5-hydroxymethyl-2-furaldehyde, and mannose and fructose cannot be absolutely separated. The results of the present study could provide a more sensitive means for 5-hydroxymethyl-2-furaldehyde and reducing sugar detection.

Key words: high performance anion exchange chromatography with electrochemical detector, HPLC with refractive index detector, 5-hydroxymethyl-2-furaldehyde, reducing sugar
\end{abstract}

\section{Short Communication}

The Maillard reaction is one of the most important and complex processes in food chemistry and processing (Moreno et al., 2003). Generally, the Maillard reaction occurs between the carbonyl group of a reducing sugar such as glucose and an amino compound, which then cyclizes to the N-substituted glycosylamine, and then forms the Amadori rearrangement product (ARP). One of the important characteristics of ARP is its ten-

Received April 15, 2012.

Accepted July 21, 2012.

${ }^{1}$ Corresponding author: shujuanyu8@gmail.com dency to undergo enolization. Degradation of the ARP by 1,2-enolizationand to form 3-deoxy-2-hexosulose has been confirmed as a main factor to produce 5-hydroxymethyl-2-furaldehyde (HMF; Hodge, 1953; Davidek et al., 2002; Moreno et al., 2003; Rufián-Henares et al., 2006; Rufián-Henares and Morales, 2007; Guan et al., 2012).

Dairy thermal treatment always produces HMF (its safety for humans uncertain) via the Maillard reaction. Some of the early studies suggested that HMF has potential toxic, mutagenic, and carcinogenic effects (Nässberger, 1990; Michail et al., 2007). A high concentration of HMF always means low quality of the dairy product. Many studies have detailed the detection of HMF using modern instruments. One of the most frequently used methods for analyzing reducing sugars and HMF is based on HPLC with various types of chromatographic columns and detectors (Davidek et al., 2005). Morales and Arnoldi (1999) performed the HPLC separation of HMF from a lactose-caseinate reaction system. Drusch et al. (1999) used a modified reversed-phase-HPLC method with o-phthalaldehyde precolumn derivatization for determination of precursors of HMF in food samples. Guan et al. (2011) used HPLC with a refractive index detector (HPLC-RID) system to analyze reducing sugars. However, HPLC techniques cannot simultaneously separate and detect reducing sugars and HMF simultaneously and are not convenient for postcolumn derivatization operation (Davidek et al., 2005).

Recently, means based on high performance anion exchange chromatography (HPAEC) coupled with an electrochemical pulsed amperometric detection or diode array detector have been reported as a powerful analytical technique for the detection and monitoring of known traces in food material (Davidek et al., 2002, 2005; Joo et al., 2008). These methods could simultaneously analyze reaction precursors and products. However, almost no research concerning the simultaneous analysis of HMF and reducing sugars has been 
Table 1. Gradient program for the high performance anion exchange chromatography with electrochemical detector (HPAEC-ECD) analysis of Maillard reaction product and reducing sugars

\begin{tabular}{lcccc}
\hline & & \multicolumn{3}{c}{ Gradient (\% by vol $)$} \\
\cline { 3 - 5 } $\begin{array}{l}\text { Retention } \\
(\mathrm{min})\end{array}$ & $\begin{array}{c}\text { Flow } \\
(\mathrm{mL} / \mathrm{min})\end{array}$ & Water & $\begin{array}{c}\mathrm{NaOH} \\
(500 \mathrm{~m} M)\end{array}$ & $\begin{array}{c}\mathrm{NaOAc}^{1} \\
\left(500 \mathrm{~m} M^{1}\right)\end{array}$ \\
\hline-10 & 1 & 97 & 3 & 0 \\
0 & 1 & 97 & 3 & 0 \\
30 & 1 & 95 & 3 & 4 \\
35 & 1 & 49 & 3 & 48 \\
40 & 1 & 49 & 3 & 48 \\
\hline
\end{tabular}

${ }^{1}$ Sodium acetate.

reported in recent literature. The aim of this work was to develop simultaneous determination of reducing sugars and HMF using an HPAEC with electrochemical detector (HPAEC-ECD) system and to compare it with the HPLC-RID method.

D-Glucose, D-fructose, and D-mannose were purchased from Shanghai Chemical Reagent Co. Ltd. (Shanghai, China). 5-Hydroxymethyl-2-furaldehyde was purchased from Sigma-Aldrich (St. Louis, MO).

The mixed solution of D-glucose $(0.1 \mathrm{mmol} / \mathrm{mL})$, D-fructose $(0.1 \mathrm{mmol} / \mathrm{mL})$, D-mannose $(0.1 \mathrm{mmol} /$ $\mathrm{mL})$, and HMF $(0.1 \mathrm{mmol} / \mathrm{mL})$ was analyzed using an HPLC-RID system. Samples were filtered through a Millex-HN nylon clarification kit of $0.45-\mu \mathrm{m}$ pore size (Millipore Corp., Bedford, MA) and then analyzed using an HPLC system. The HPLC system configuration was as follows: chromatogram controller: Waters 600 (Waters Corp., Milford, MA), pump: Waters 600E (Waters Corp.), injector: Rheodyne 7725i manual injector (Waters Corp.), and detector: Waters 2414 refractive index detector (Waters Corp.). The HPLC-RID analysis using Sugar-pak1 $6.5 \times 300 \mathrm{~mm}$ ion-exchange chromatography (Waters Corp.) was preformed as follows: the injection volume was $5 \mu \mathrm{L}$ and the mobile phase was a 50-mg/L EDTA-Ca water solution delivered at a flow rate of $0.5 \mathrm{~mL} / \mathrm{min}$. The column temperature was set at $90^{\circ} \mathrm{C}$. The chromatography running time was 30 min. The HPLC peaks were identified to be D-glucose, D-fructose, D-mannose, and HMF by comparing the retention time between them and standard compounds.

The HPAEC-ECD analysis was done according to the literature, with a slight modification (Davidek et

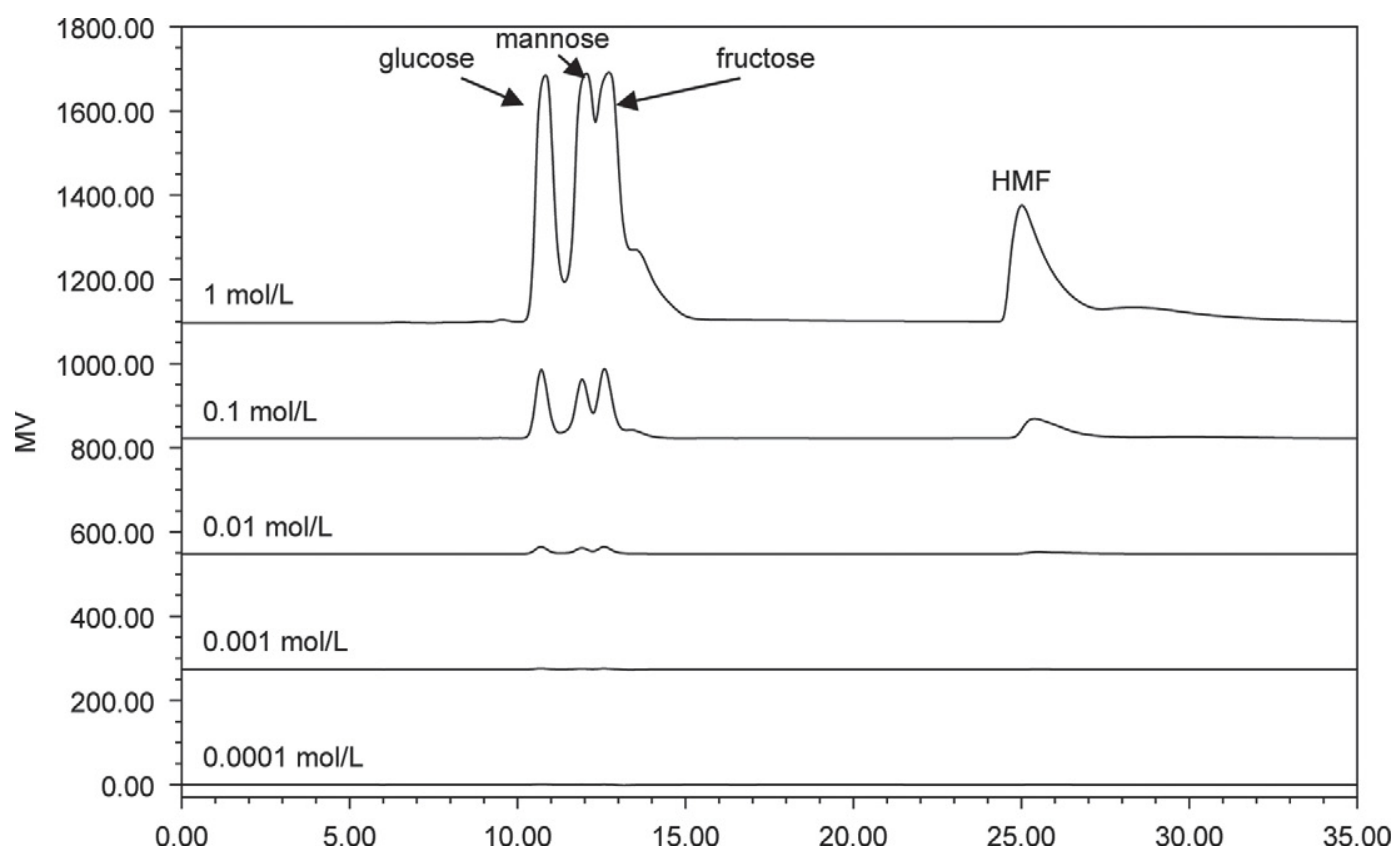

Figure 1. High performance liquid chromatography with refractive index detector (HPLC-RID) analysis of reducing sugars and 5-hydroxymethyl-2-furaldehyde (HMF). 
al., 2003). The mixed solution of D-glucose $(0.1 \mathrm{mmol} /$ $\mathrm{mL})$, D-fructose $(0.1 \mathrm{mmol} / \mathrm{mL})$, D-mannose $(0.1 \mathrm{mmol} /$ $\mathrm{mL})$, and $\mathrm{HMF}(0.1 \mathrm{mmol} / \mathrm{mL})$ were filtered through a Millex-HN nylon clarification kit of $0.45-\mu \mathrm{m}$ pore size (Millipore Corp.), and then analyzed by a DX 5000 Dionex system (Dionex Corp., Sunnyvale, CA), a gradient pump (model EG40) with online degassing, and an electrochemical detector (model ED40). Separation was accomplished by a CarboPac PA1 anion exchange column $(250 \times 4 \mathrm{~mm}$; Dionex Corp. $)$ and a CarboPac PA1 guard column $(50 \times 4 \mathrm{~mm}$; Dionex Corp. $)$ with a constant flow rate of $1 \mathrm{~mL} / \mathrm{min}$ throughout the program (the gradient is shown in Table 1). The injection volume was $10 \mu \mathrm{L}$.

D-Glucose, D-fructose, D-mannose, and HMF always have different charges and could be reserved by cation or anion stationary phases. As shown in Figure 1, HMF, D-glucose, D-fructose, and D-mannose could be detected by RID. However, it was difficult to separate mannose and fructose, as the reducing sugars concentration was $1 \mathrm{~mol} / \mathrm{L}$. Even at a concentration of 0.1 $\mathrm{mol} / \mathrm{L}$, mannose and fructose could not be absolutely separated. Moreover, HMF produced a tailing peak, as the concentration was 0.1 and $1 \mathrm{~mol} / \mathrm{L}$, and almost no peak was observed, as the concentration was 0.001 $\mathrm{mol} / \mathrm{L}$ or lower than $0.001 \mathrm{~mol} / \mathrm{L}$, which means that the lowest detectable limit (LDL) using the HPLCRID system for reducing sugars and HMF simultaneous detection was no lower than $0.001 \mathrm{~mol} / \mathrm{L}$ in this experiment. Therefore, HPLC-RID was not suitable for reducing sugars and HMF simultaneous detection at a low concentration.

As the HPAEC-ECD with a CarboPac PA1 anion exchange column was used for separation and determination, D-glucose, D-fructose, D-mannose, and HMF could be separated and detected simultaneously when the concentration was from 0.00005 to $0.01 \mathrm{~mol} / \mathrm{L}$ (Figure 2). The standard lines of HMF and reducing sugars are shown in Figure 3. However, mannose and fructose could not be completely separated if the concentration was $0.01 \mathrm{~mol} / \mathrm{L}$ or higher than $0.01 \mathrm{~mol} / \mathrm{L}$. The reason for this was that CarboPac PA1 anion exchange column was overloaded when the reducing sugar and HMF injection concentration was $0.01 \mathrm{~mol} / \mathrm{L}$ or higher than $0.01 \mathrm{~mol} / \mathrm{L}$. On the other hand, almost no peak of reducing sugars and HMF could be observed when the concentration was $0.00001 \mathrm{~mol} / \mathrm{L}$, whereas both reducing sugars and HMF peaks were observed when

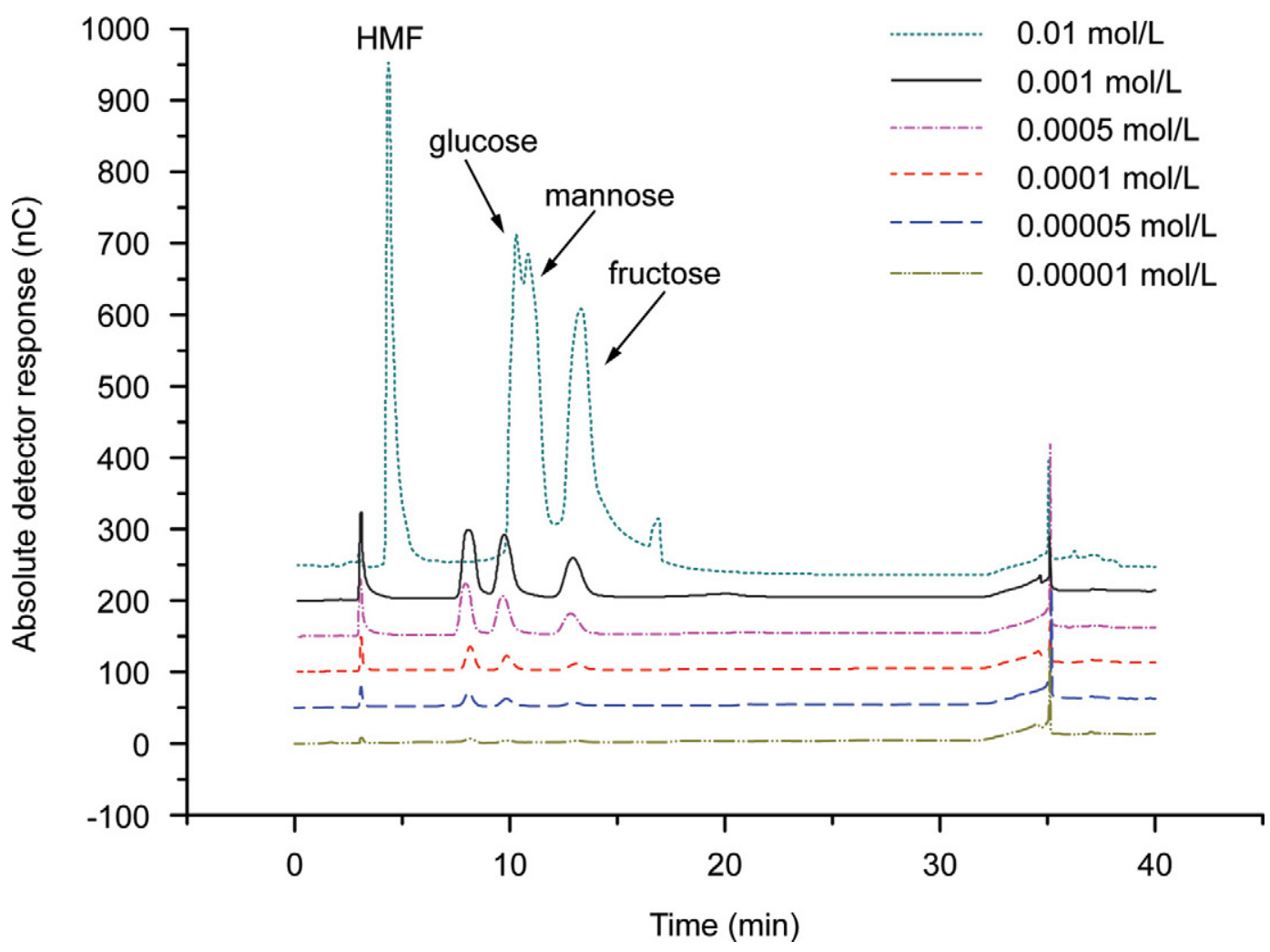

Figure 2. High performance anion exchange chromatography with electrochemical detector (HPAEC-ECD) analysis of reducing sugars and 5-hydroxymethyl-2-furaldehyde (HMF). Color version available in the online PDF. 

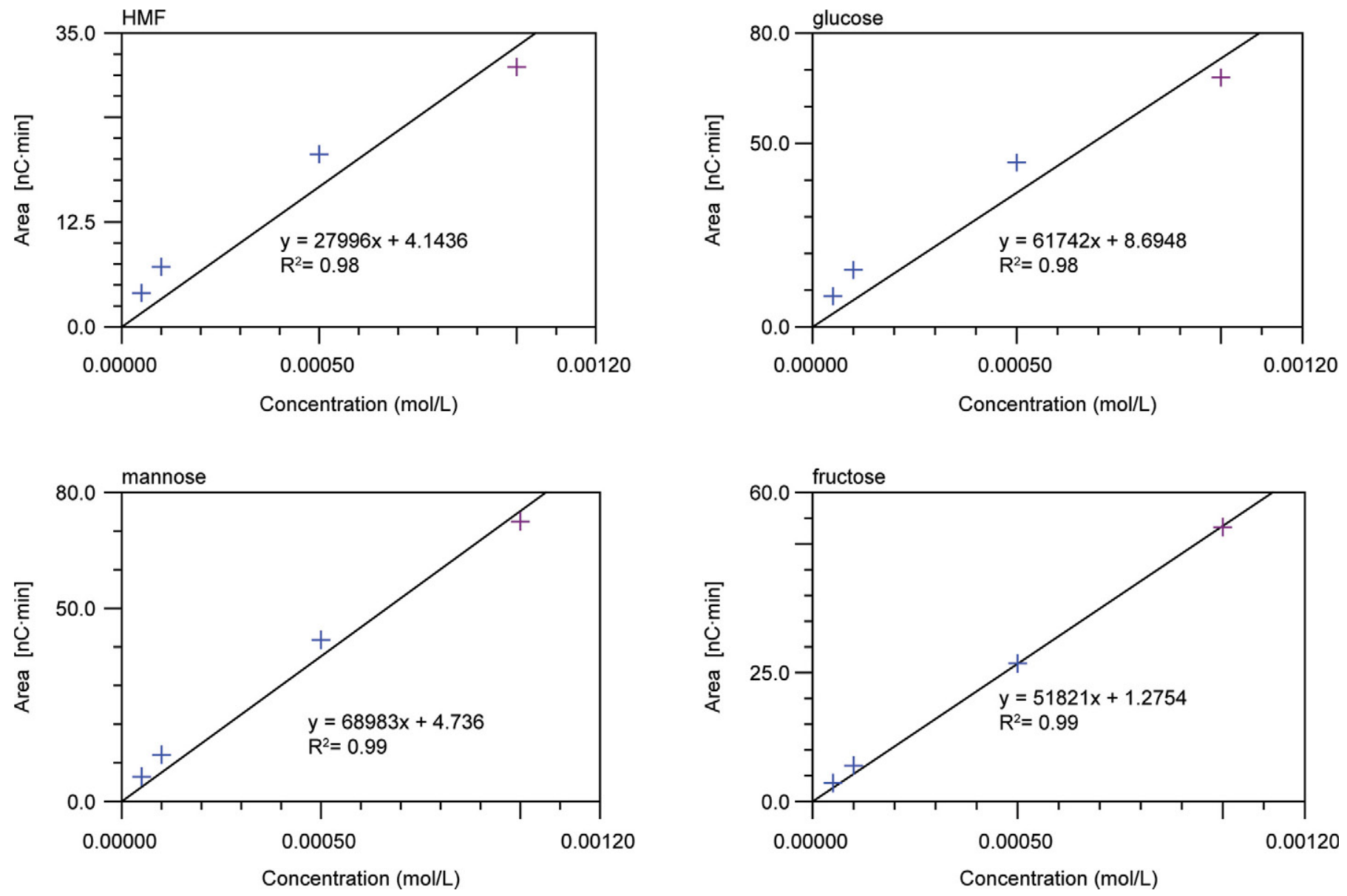

Figure 3. Standard lines of reducing sugars and 5-hydroxymethyl-2-furaldehyde (HMF) using high performance anion exchange chromatography with electrochemical detector (HPAEC-ECD) analysis. Color version available in the online PDF.

the concentration was $0.00005 \mathrm{~mol} / \mathrm{L}$, which means that the LDL using HPAEC-ECD to detect D-glucose, D-fructose, D-mannose, and HMF was $0.00005 \mathrm{~mol} / \mathrm{L}$ in this experiment. Thus, it can be seen that HPAECECD is more suitable for trace analysis of reducing sugars and HMF.

The HPAEC-ECD system with a CarboPac PA1 anion exchange column was more suitable for separating and detecting reducing sugars and HMF than HPLCRID at a trace concentration. The LDL of reducing sugars and HMF was $0.00005 \mathrm{~mol} / \mathrm{L}$ using HPAECECD.

\section{ACKNOWLEDGMENTS}

All authors acknowledge the National Science Foundation of China (Beijing, China; grant no. 31071564), the Science Foundation of Guangdong Province of China (grant no.10251064101000014), and the Fundamental Research Funds for the Central Universities (China; 2011ZP009) for financial support.

\section{REFERENCES}

Davidek, T., N. Clety, S. Aubin, and I. Blank. 2002. Degradation of the Amadori compound N-(1-deoxy-D-fructos-1-yl)glycine in aqueous model systems. J. Agric. Food Chem. 50:5472-5479.

Davidek, T., N. Clety, S. Devaud, F. Robert, and I. Blank. 2003. Simultaneous quantitative analysis of Maillard reaction precursors and products by high-performance anion exchange chromatography. J. Agric. Food Chem. 51:7259-7265.

Davidek, T., K. Kraehenbuehl, S. Devaud, F. Robert, and I. Blank. 2005. Analysis of Amadori compounds by high-performance cation exchange chromatography coupled to tandem mass spectrometry Anal. Chem. 77:140-147.

Drusch, S., V. Faist, and H. F. Erbersdobler. 1999. Determination of $\mathrm{N}^{\epsilon}$-carboxymethyllysine in milk products by a modified reversedphase HPLC method. Food Chem. 65:547-553.

Guan, Y.-G., W.-H. Shi, S.-J. Yu, and X.-B. Xu. 2011. Ultrafiltration of caramel color solutions reduces 5-hydroxymethyl-2-furaldehyde. J. Membr. Sci. 380:9-12.

Guan, Y.-G., S.-L. Wang, S.-J. Yu, S.-M. Yu, and Z.-G. Zhao. 2012. Changes in the initial stages of a glucose-proline Maillard reaction model system influences the dairy quality during thermal processing. J. Dairy Sci. 95:590-601.

Hodge, J. E. 1953. Dehydrated foods, chemistry of browning reactions in model systems. J. Agric. Food Chem. 1:928-943.

Joo, K.-M., C.-W. Park, H.-J. Jeong, S. J. Lee, and I. S. Chang. 2008 Simultaneous determination of two Amadori compounds in Korean red ginseng (Panax ginseng) extracts and rat plasma by high- 
performance anion-exchange chromatography with pulsed amperometric detection. J. Chromatogr. B Analyt. Technol. Biomed. Life Sci. 865:159-166.

Michail, K., V. Matzi, A. Maier, R. Herwig, J. Greilberger, H. Juan, O. Kunert, and R. Wintersteiger. 2007. Hydroxymethylfurfural: An enemy or a friendly xenobiotic? A bioanalytical approach. Anal. Bioanal. Chem. 387:2801-2814.

Morales, F. J., and A. Arnoldi. 1999. Analysis of galactosylisomaltol in milk systems using HPLC. Food Chem. 67:185-191.

Moreno, F. J., E. Molina, A. Olano, and R. López-Fandiño. 2003. High-pressure effects on Maillard reaction between glucose and lysine. J. Agric. Food Chem. 51:394-400.
Nässberger, L. 1990. Influence of 5-hydroxymethylfurfural (5-HMF) on the overall metabolism of human blood cells. Hum. Exp. Toxicol. 9:211-214.

Rufián-Henares, J. Á., E. Guerra-Hernandez, and B. García-Villanova. 2006. Colour measurement as indicator for controlling the manufacture and storage of enteral formulas. Food Contr. 17:489-493.

Rufián-Henares, J. A., and F. J. Morales. 2007. Effect of in vitro enzymatic digestion on antioxidant activity of coffee melanoidins and fractions. J. Agric. Food Chem. 55:10016-10021. 